\title{
THE
}

\section{Rain in Shallow Cumulus Over the Ocean: The RICO Campaign}

Robert M. Rauber

Brian G. Heikes

University of Rhode Island, bheikes@uri.edu

et al

Follow this and additional works at: https://digitalcommons.uri.edu/gsofacpubs

Terms of Use

All rights reserved under copyright.

\section{Citation/Publisher Attribution}

Rauber, R. M., Stevens, B., Ochs, H. T., III, Knight, C., Albrecht, B. A., Blyth, A. M., Fairall, C. W.,...Zuidema, P. (2007). Rain in Shallow Cumulus Over the Ocean: The RICO Campaign. Bulletin of the American Meteorological Society, 88, 1912-1928. doi: 10.1175/BAMS-88-12-1912

Available at: https://doi.org/10.1175/BAMS-88-12-1912

This Article is brought to you for free and open access by the Graduate School of Oceanography at DigitalCommons@URI. It has been accepted for inclusion in Graduate School of Oceanography Faculty Publications by an authorized administrator of DigitalCommons@URI. For more information, please contact digitalcommons-group@uri.edu. 


\section{RAININ SHALLOW GUMULUS OVER THE OCEAN The Rico Campaign}

by Robert M. Rauber, Bjorn Stevens, Harry T. Ochs III, Charles Knight,

B. A. Albrecht, A. M. Blyth, C. W. Fairall, J. B. Jensen, S. G. Lasher-Trapp,

O. L. Mayol-Bracero, G. VAli, J. R. Anderson, B. A. Baker, A. R. Bandy,

E. Burnet, J.-L. Brenguier, W. A. Brewer, P. R. A. Brown, P. Chuang,

W. R. Cotton, L. Di Girolamo, B. Geerts, H. Gerber, S. Goke, L. Gomes,

B. G. Heikes, J. G. Hudson, P. Kollias, R. P. Lawson, S. K. Krueger,

D. H. Lenschow, L. Nuijens, D. W. O'Sullivan, R. A. Rilling,

D. C. Rogers, A. P. Siebesma, E. Snodgrass, J. L. Stith, D. C. Thornton,

S. TUCKER, C. H. TWOHY, AND P. ZUIDEMA

\section{S. TUCKER, C. H. TWOHY, AND P. ZUIDEMA}




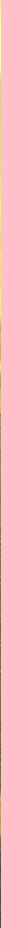

$\mathrm{t}$ is well known that shallow maritime cumuli can rapidly form rain. Systematic studies, dating back to Byers and Hall (1955), suggest that rain first appears in maritime cumuli when their tops reach about $2 \mathrm{~km}$, and is ubiquitous by the time the tops reach $3.5 \mathrm{~km}$. Saunders (1965) showed that maritime cumuli whose tops eventually reach $3.5 \mathrm{~km}$ can develop from cumulus fractus in $25-35 \mathrm{~min}$, and that the

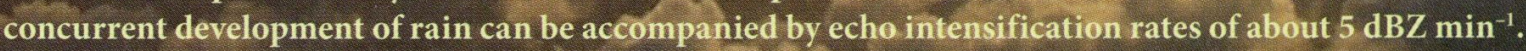
Such measurements add substance to the remark by Squires (1958) that maritime clouds with tops greater than $2500 \mathrm{~m}$ "usually rain within half an hour."

The tendency of shallow maritime cumulus to readily form rain has motivated research into mechanisms of rain formation in warm clouds for more than half a century. Certainly, the motivation for this research has shifted; funding agencies were initially interested in the possibility of intentionally modifying clouds so as to increase their propensity to 
precipitate, but now research is funded because of a concern that humanity may be unintentionally modifying the cloud environment in ways that decrease the propensity of shallow cumuli to precipitate and affect cloud fraction and planetary albedo (e.g., Albrecht 1989). The basic scientific questions have sharpened and expanded in light of these new concerns; for example, if humans are modifying the propensity of clouds to rain, how important is this to the properties of individual clouds on the one hand, and the statistics of cloud ensembles on the other?

We have witnessed an increasing appreciation of the role played by shallow maritime (trade wind) cumuli in the general circulation of the atmosphere (see review by Stevens 2005). Budget studies, beginning with the work of Riehl et al. (1951) in the northeast trades of the Pacific and continuing with the Atlantic Tradewind Experiment (ATEX; Augstein et al. 1973) and the Barbados Oceanographic and Meteorological Experiment (BOMEX; Nitta and Esbensen 1974) in the northwest trades of the Atlantic, demonstrated that the moisture transport from shallow cumulus convection plays an essential role in the hydrological cycle, effectively setting the depth of the trade wind layer and hence the rate of surface evaporation (cf. Betts 1973; Stevens 2007). Such results are consistent with the marked sensitivity to the representation of shallow convection in both medium-range weather forecast models and simplified models of the tropical climate (Tiedtke 1989; Neggers et al. 2007). Shallow trade wind convection is also emerging as central to the question of climate change, because differences in the representation of trade wind clouds appear to explain much of the difference in model-based estimates of climate sensitivity (Bony and Dufresne 2006; Wyant et al. 2006; Medeiros et al. 2007, manuscript submitted to J. Climate).

Precipitation formation in warm clouds and the statistical behavior of fields of shallow cumuli are usually associated with processes that occur on scales of centimeters or less on the one hand, and tens of kilometers or more on the other. Both are connected by cloud-scale processes, such as mixing, entrainment, and evaporation. Entrainment, the process whereby air in the vicinity of the cloud is incorporated into the turbulent cloud-scale circulation, is essential to both the subsequent microphysical evolution of individual clouds (e.g., Ludlam and Saunders 1956; Brenguier and Grabowski 1993), as well as the macrophysical evolution of the cloud layer as a whole (see review by Siebesma 1998). Thus, it is not surprising that studies of how clouds entrain, mix, and otherwise interact with their local environment also date back to the middle of the last century (Stommel 1947). While the past $60 \mathrm{yr}$ has witnessed some advancement in our understanding of these issues, many basic questions remain (see Blyth 1993, for a review). When precipitation is considered, new questions also emerge. For instance, are cold pools from evaporating rain important to the subsequent organization of fields of shallow convection? More broadly, to what extent do cloud-scale processes determine relationships between precipitation and cloud amount (cf., Xue et al. 2007)? While it should be clear that even a phenomenon as simple as shallow
AfFiliations: RaUBer, OCHS, Di Girolamo, GOKE, AND SNODGRASS - University of Illinois at Urbana-Champaign, Urbana, Illinois; STEVENS - University of California, Los Angeles, Los Angeles, California; KNIGHT, Jensen, LeNSCHOW, RILLING, ROgers, AND STITHNational Center for Atmospheric Research, Boulder, Colorado; AlBRECHT AND ZUIDEMA-University of Miami, Miami, Florida; BLYTH-University of Leeds, Leeds, United Kingdom; FaIRALL, BREWER, AND TUCKER - NOAA/ETL, Boulder, Colorado; LASHER-TRAPP-Purdue University, West Lafayette, Indiana; MAYOL-BrACERO-University of Puerto Rico-Río Piedras, San Juan, Puerto Rico; VAli AND GeerTsUniversity of Wyoming, Laramie, Wyoming; ANDERSON-Arizona State University, Tempe, Arizona; BAKER AND LAWSON-SPEC, Inc., Boulder, Colorado; BANDY AND THORNTON-Drexel University, Philadelphia, Pennsylvania; BURnet, Brenguier, AND GOMES-CNRMI GAME, Météo-France/CNRS, Toulouse, France; BrowN-Met Office, Exeter, United Kingdom; CHUANG-University of California, Santa Cruz, Santa Cruz, California; COTTON-Colorado State University, Fort Collins, Colorado; Gerber-Gerber Scientific, Inc., Reston, Virginia; HEIKES-University of Rhode Island, Narragansett,
Rhode Island; HuDSON-Desert Research Institute, University of Nevada, Reno, Nevada; Koluıs-Brookhaven National Laboratory, Upton, New York; KRUEGER-University of Utah, Salt Lake City, Utah; NUujens-University of California, Los Angeles, Los Angeles, California, and Wageningen University, Wageningen, Netherlands; O'SULLIVAN-U.S. Naval Academy, Annapolis, Maryland; SIEBESMARoyal Netherlands Meteorological Institute, De Bilt, Netherlands; TwOHY-Oregon State University, Corvallis, Oregon A supplement to this article is available online (DOI:10.1175/BAMS88-12-Rauber)

CORRESPONDING AUTHOR: Robert M. Rauber, Department of Atmospheric Sciences, University of Illinois at Urbana-Champaign, 105 South Gregory St., Urbana, IL 61801

E-mail: rauber@atmos.uiuc.edu

The abstract for this article can be found in this issue, following the table of contents.

DOI:10.1175/BAMS-88-12-1912

In final form 19 June 2007

(C)2007 American Meteorological Society 
maritime convection embodies a diverse set of questions spanning a rich range of scales, for practical reasons past fieldwork has tended to focus on specific issues occurring over a relatively narrow range of scales.

The field campaign was developed around the idea that new insights, especially as they relate to the initiation and effects of precipitation, were most likely to emerge from an observational strategy that emphasized the interplay of diverse physical processes. Doing so necessitated taking measurements that spanned the widest possible range of scales. Advancements in remote sensing, both surface and satellite based, and new instruments capable of providing unprecedented measurements of quantities, such as the finescale structure of the droplet spectrum, the transport of trace gases by cloud-scale processes, and the distribution of the atmospheric aerosol, made it possible to conceive of such an approach. This article describes RICO, the realization of this strategy.

THE FIELD CAMPAIGN. RICO took place during November 2004-January 2005 off the Caribbean islands of Antigua and Barbuda within the northeast trades of the western Atlantic. The time period was selected to avoid tropical cyclones and maximize opportunities to sample shallow convection. Operations were centered around the domain of the NCAR SPolKa dual-polarization, dual-wavelength ( $\mathrm{S}$ and $\mathrm{K}$ band) radar system (Fig. 1). Four mobile systems (three aircraft and a research ship) targeted clouds within the SPolKa domain. The three aircraft, the NSF/NCAR Hercules C130Q (hereafter the C130), the University of Wyoming King Air 200T (the King Air), and the FAAM BAE 146-301 (the BAE-146) aircraft, were based at the V. C. Bird International Airport near St. John's, Antigua, and flew a combined total of 57 missions (nearly 350 flight hours). The RVSJ was centered in the region of concentrated SPolKa scanning and flight measure- ments, roughly $25 \mathrm{~km}$ north-northeast of Barbuda (see Fig. 1). A description of its measurement systems and strategies are discussed in "High-resolution cloud and boundary layer measurements on the high seas" sidebar. RICO operations were supported by a rawinsonde and surface meteorological systems at Spanish Point, a spit of land on the southeast tip of Barbuda. Except for brief periods of southwesterly flow, the sounding site allowed the sondes to ascend over the ocean without passing over the island or in its wake. Three ground-based aerosol sampling systems were deployed-one on Antigua and two on Puerto Rico (see the "Ground-based aerosol measurements during RICO" sidebar). Data from both geostationary and low-Earth-orbiting satellites were also archived. The BAE-146, the RVSJ, and the Antigua aerosol site operated only in January.

Radar scans were designed to collect a large quantity of data for statistical analysis of rainfall, to document the time of initiation of clouds and rainfall, and to characterize the full life cycle of a large number of clouds at high temporal resolution. The routine scan sequence consisted of volume scans over a $180^{\circ}$ sector. Each volume was filled using a sequence of constant- 


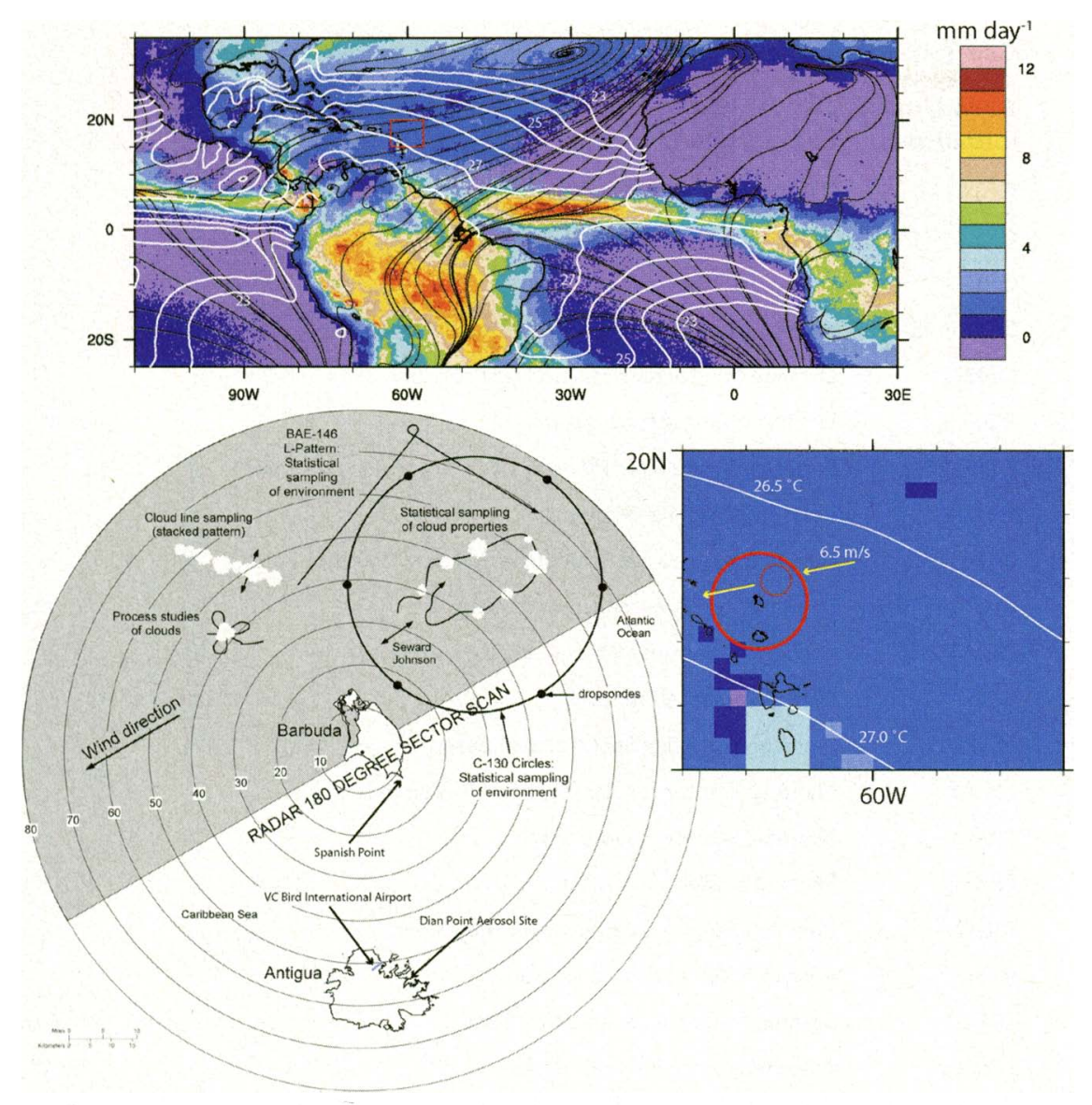

FIG. I. RICO experimental area, sampling strategy, and climatology. to, but still below, cloud base (typically near $400 \mathrm{~m}$ ) to characterize the subcloud aerosol, and one at $4.6-\mathrm{km}$ altitude to deploy dropsondes and survey the cloud field with the EOL SABL looking downward. A 4-h time period between sets of circles was reserved for cloud sampling. During nearly all flights, clouds were sampled semirandomly at fixed altitudes for periods of $30-60 \mathrm{~min}$. The effect of this strategy is evident in the height distribution of the C130 measurements (see Fig. 5, discussed below). During some flights when large congestus cloud clusters or cloud lines were present, cross-band passes at several altitudes were flown to study the raindrop spectrum and aerosol processing by clouds. The BAE-146 missions were similar to those of the C130, elevation-angle (PPI) scans, with the elevation angle of the uppermost scan chosen based on the height of the clouds, and the midangle of the sector aligned perpendicularly to the mean echo track. Defining a volume in this manner reduced the time necessary to complete the volume scan (thereby allowing better temporal resolution), but kept individual clouds in view as long as possible, thus allowing documentation of their life cycles. We also conducted a full surveillance scan at $0.5^{\circ}$ elevation at roughly 20 -min intervals through the duration of the project. Special scans were carried out during satellite overpasses and for studies of lines of island-induced cloud downwind of Barbuda. The radar, rawinsonde, and ground-sampling systems operated on a 24-h basis, with rawinsonde launches on 12-, 6-, or 3-hourly schedules, depending on specific aircraft missions.

The aircraft conducted statistical sampling, process studies, and coordinated studies. The C130 and BAE-146 devoted most of their time to statistical sampling: C130 flights began and ended with three $60-\mathrm{km}$-diameter circles, with one $100 \mathrm{~m}$ above the ocean surface to characterize the near-surface aerosol and estimate surface fluxes, one nearer focusing on statistical sampling of clouds and aerosol. The King Air took advantage of its W-band cloud radar and emphasized process studies, selecting clouds based on their size and expected longevity for repeated sampling. On several occasions, pairs of aircraft were able to coordinate closely in order to sample the same clouds nearly simultaneously at different altitudes. These data may be valuable in determining the representativeness of single-aircraft data taken at different times and altitudes in rapidly evolving cloud cells, and hence may help establish the value of such data to support cloud process studies.

Figure 2 illustrates the range of scales sampled during RICO. Most of the measurements here are in reference to one particular cloud, penetrated by the Wyoming King Air at 1359 UTC 17 January. The context for data such as those illustrated in the figure is provided by soundings, satellite measurements, and, on most days, the surveillance circle data from the $\mathrm{C} 130$. The figure emphasizes the potential of the multiplatform, multiscale measurements made during RICO, but also some of the challenges. For instance, the C130 did not fly on this day, and so images of the subcloud aerosol such as those shown 


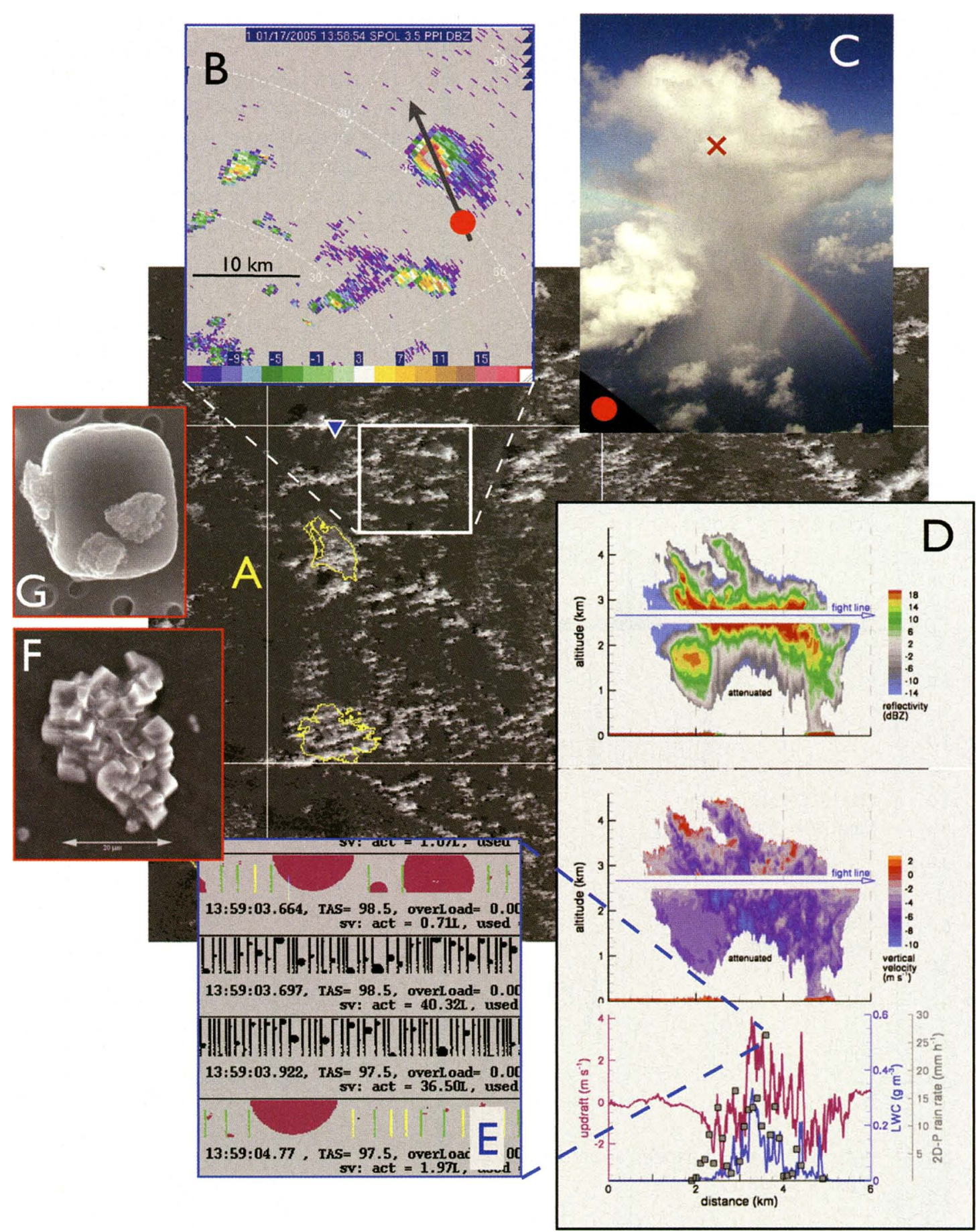

FIG. 2. Observations on many scales of a precipitating small cumulus (I359 UTC I7 Jan). (a) Satellite image from DMSP recorded 10 min before penetration by the Wyoming King Air. (b) S-Pol radar image at $3.5^{\circ}$ elevation; the cloud is about $46 \mathrm{~km}$ from the radar. (c) Photograph taken from a position marked with the red dot in (b). The cross marks the approximate location of the aircraft penetration at $2630-\mathrm{m}$ altitude. (d) Vertical sections of radar reflectivity and of Doppler velocity from the Wyoming Cloud Radar and plots of the in situ updraft, liquid water content, and rain-rate measurements. Note that the high rain rates and large drops are within the updraft. (e) Millimetersized drops seen at two different magnifications from imaging probes on the King Air. Also shown are scanning electron microscope images, such as were made from data collected on NSF/NCAR $\mathrm{Cl} 30$ subcloud circles: (f) 2- $\mu \mathrm{m}$ sea-salt particles collected by the total aerosol sampler and (g) giant sea salt particles (2- $\mu \mathrm{m}$ scale) collected with the giant nuclei sampler. The location of the Research Vessel Seward Johnson is marked with a blue triangle in (a). 
in Fig. 2 are from a different flight. Piecing together data sampled inhomogeneously in space and time is a challenge, but can be addressed because of the statistical sampling approach employed.

Figure 3 presents a broad summary of the meteorological conditions during RICO derived from the soundings and radar surveillance scans, along with the days on which the aircraft and the ship were deployed. The full suite of instrumentation provided by the mobile and land-based platforms is summarized in the electronic supplement to this document (online at doi:10.1175/BAMS-88-12-Rauber). To develop an appreciation of the types of data collected, below we discuss subsets of the RICO data in the context of three specific questions chosen to span the range of scales sampled during the project.
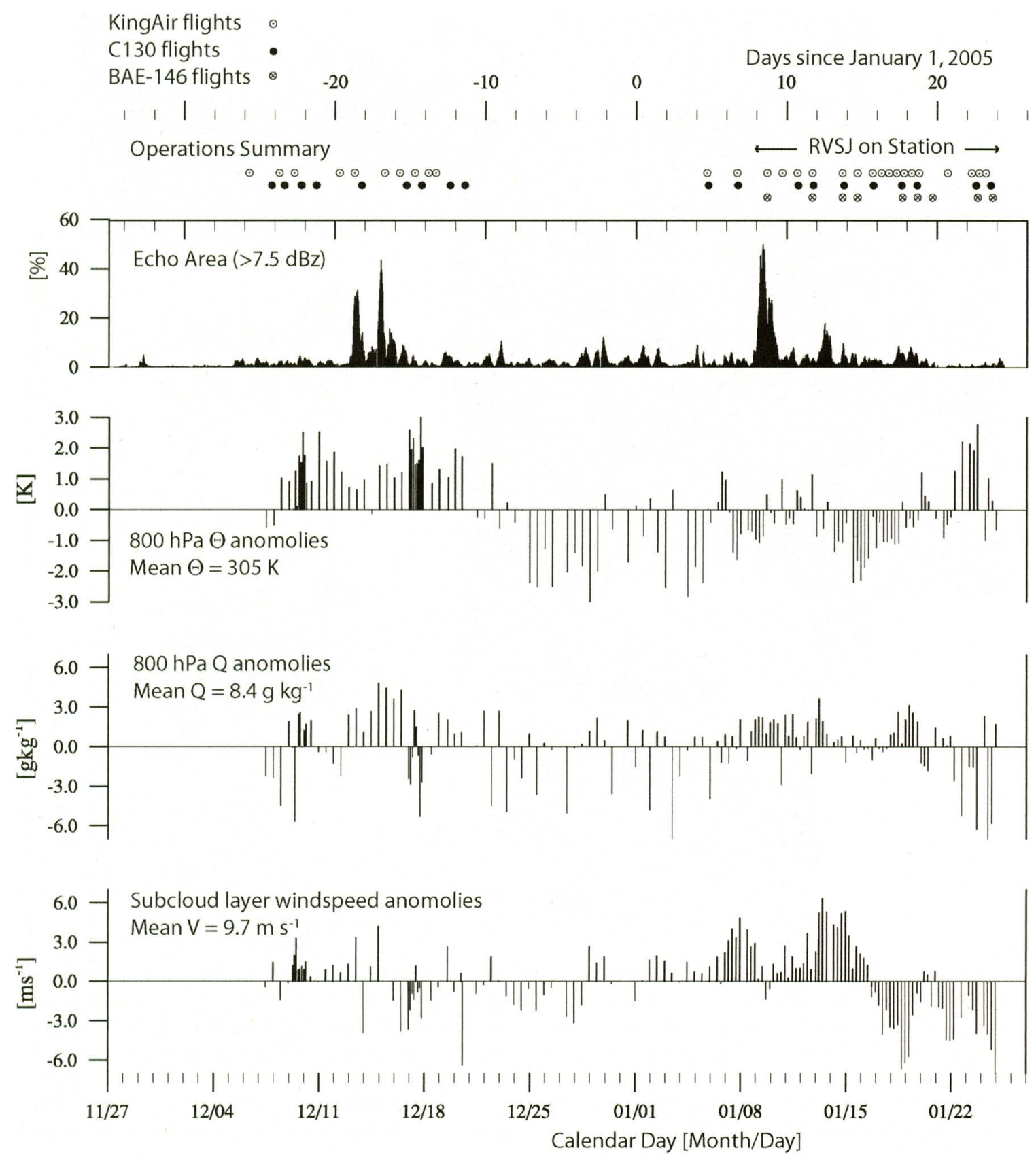

FIG. 3. Platform deployment and meteorological variability during RICO: (top) the deployment periods of different platforms versus time and (bottom, from top to bottom) echo area from surveillance scans, potential temperature and moisture anomalies at $800 \mathrm{hPa}$, and subcloud wind speed anomalies. Mean conditions are indicated in text on each panel. Each bar in lower panels corresponds to an individual Spanish Point rawinsonde. 
Questions and measurements. RAIN INITIATION. What processes regulate the evolution of the cloud-droplet spectrum in shallow maritime cumulus convection so that rain forms? Diffusional growth theory adequately accounts for the early stages of cloud-droplet development, but fails to explain the spectral breadth of observed drop-size distributions. A variety of mechanisms have been forwarded to explain spectral broadening, a requirement for the onset of significant collision and coalescence. One mechanism is that a small fraction of cloud droplets form on giant and ultragiant nuclei, forming larger droplets that then grow immediately through collisions with, and coalescence of, smaller drops (Houghton 1938; Woodcock 1953; Johnson 1982). It is also possible that the processing and recirculation of droplets by the same or neighboring clouds may also contribute to rain initiation (Rauber et al. 1991; Kogan 1993). Some mechanisms invoke ways in which the turbulent structure of the cloud affects the drop spectrum. These turbulence theories range from processes that may influence condensation through fluctuations in supersaturation and/or an increase in collision rates (e.g., Cooper 1989; Srivastava 1989; Shaw 2003), to theories that depend on the ability of turbulence to homogenize air parcels with diverse histories (e.g., Ludlam and Saunders 1956; Latham and Reed 1977; Baker and Latham 1979; Telford et al. 1984). A goal of RICO was to obtain the observations that could help us understand the relative importance of these different mechanisms.

Field investigation of processes leading to rain initiation can be usefully constrained by a characterization of the subcloud aerosol spectrum and drop spectra within clouds, as well as updraft structure, entrainment rates, and cloud and environmental thermodynamic properties. In RICO, a wide variety of particle spectrometers based on different measuring principles were deployed on each of the three aircraft to obtain redundant measurements across the full aerosol, and the cloud- and raindrop spectrum. As detailed in the electronic supplement (online at doi:10.1175-BAMS-88-12-Rauber), these measurements were based on both standard probes, as well as new techniques, including a new two-dimensional stereo-imaging probe (Lawson et al. 2006), the California Institute of Technology phase Doppler interferometer, and the French redesigned Fast FSSP (Brenguier et al. 1998). The composition of the aerosol was measured from the $\mathrm{C} 130$ using slides and electron microscopy and with continuous measurements from surface stations (e.g., the "Ground-based aerosol measurements during RICO" sidebar, which describes chemical measurements made at Dian Point). The turbulent structure of the cloud and subcloud layer and its thermodynamic state were measured by standard techniques, while the clouds and rain shafts were also sampled by an array of both land-based and mobile remote sensors. The evolution of the radar reflectivity factor and differential reflectivity within growing clouds, together with in situ particle measurements, provide strong constraints that can be applied to the evaluation of model simulations of cloud growth and precipitation.

ENTRAINMENT, MIXING, AND CLOUD PROCESSING. How does entrainment, mixing, and cloud processing modify clouds and the cloud layer? Subcloud trace gases and aerosol are chemically and physically transformed when processed by cloud droplets. Chemically, reactive trace gases (e.g., sulfur dioxide) can dissolve into cloud droplets and oxidize, increasing the mass of dissolved substance within the droplets. Physically, as a collector drop grows by collision with other droplets, the dissolved substance within the collector increases. Detrainment and evaporation in either case results in an aerosol population with different chemistry and a different size distribution. Measurements in RICO were designed to utilize chemical and physical transformations such as these, as well as standard tracer analyses to investigate the sources and amounts of entrained air, the lifetime of individual clouds, and the net effect of entrainment on the aerosol distribution within the trade wind layer (Blyth 1993; Brenguier and Grabowski 1993; Siebesma 1998; Lasher-Trapp et al. 2005).

To improve the capability of tracer analysis, the C130 during RICO was instrumented with measurements of ozone $\left(\mathrm{O}_{3}\right)$, carbon monoxide (CO), and dimethylsulfide (DMS) sensors at $1 \mathrm{~Hz}$ or better. These three substances are long lived as compared to typical convective time scales, and thus act as chemical tracers that can be used in conjunction with thermodynamic tracers to investigate entrainment, even under conditions where precipitation is present and radiative heating is not negligible. Dimethyl sulfide, in particular, has been shown to be a particularly effective tracer of mixing processes in the marine boundary layer (Stevens et al. 2003; Faloona et al. 2005). In addition, the reactive trace gases sulfur dioxide, hydrogen peroxide, and methylhydroperoxide were also measured on the C130. Measurements of cloud water hydrogen peroxide and methylhydroperoxide were also attempted using a CVI (Twohy et al. 1997). These measurements may help bound the time elapsed since air parcels left the subcloud layer, thus 
constraining cloud age, as well as providing insight into gas and aqueous-phase sulfur dioxide oxidation leading to aerosol formation.

HOW MUCH DOES IT RAIN? Using data from the TRMM $\mathrm{K}_{u}$-band radar, Short and Nakamura (2000) estimated that rain from shallow clouds (those whose tops are most often between 2 and $3 \mathrm{~km}$ ) contribute slightly more than $20 \%$ of the total rainfall over the tropical ocean. But, the possibility remains that shallow cumulus, whose reflectivities (averaged over the volume sampled by the TRMM radar beam) may often be below the 17- $\mathrm{dBZ}$ detection limit, contribute significantly more rain than is seen by the TRMM radar. How do clouds of different depths and different forms of organization contribute to the observed surface precipitation? And to what extent do clouds with different mesoscale organization contribute to the actual rain rate?
RICO measurements were designed to help answer these questions. The 8 weeks of nearly continuous volume scanning by the $S$-band radar provides an extraordinary database from which the statistics of shallow rain can be explored (see, e.g., Nuijens 2005; Snodgrass 2006). To help interpret these echo statistics, a variety of other instrumentation was also deployed. The shorter-wavelength radars deployed in RICO (X, K, and W band) provide useful checks on the S-band data at reflectivity factors below about $5 \mathrm{dBZ}$, where Bragg scattering may cause ambiguities (Knight and Miller 1998). The X-, K-, and W-band shipboard radars (see sidebar "High-resolution cloud and boundary layer measurements on the high seas") and the W-band measurements from the King Air also provide much higher resolution images of the cloud (e.g., Fig. 2) that we are using to explore structures not well resolved by the $\mathrm{S}$-band measurements. In particular, the vertically pointing modes of these

\section{HIGH-RESOLUTION CLOUD AND BOUNDARY LAYER MEASUREMENTS ON THE HIGH SEAS}

$D_{w}^{u+m}$ uring RICO the R/V Seward Johnson was instrumented with a unique suite of in situ and remote sensing systems to provide key cloud and boundary layer observations. These observations represent the most comprehensive set of measurements of cloud structures, cloud fields, surface fluxes, and boundary layer structures associated with fair-weather cumuli. Observing systems on the ship included a flux tower for estimating the surface energy, moisture, and momentum fluxes [See (a), below]. Radiosondes launched 4-6 times daily provided the boundary layer thermodynamic structure, and a motion-stabilized $915-\mathrm{MHz}$ wind profiler provided continuous observations of the boundary layer winds, refractive index, and precipitation (c). A microwave radiometer gave continu- ous estimates of cloud liquid water path and water vapor path. Cloud-based heights were measured with a laser ceilometer. Three radars - a scanning $35-\mathrm{GHz}$ (Ka band) radar, an upward-facing Doppler $94-\mathrm{GHz}$ (W band) radar, and a $9.4-\mathrm{GHz}$ ( $X$ band) radar (c) -operating from the ship characterized cloud structures. A scanning, motion-compensated lidar provided observations of both subcloud layer vertical velocities when used in an upward-facing mode and radial wind components extending out about $6 \mathrm{~km}$ from the ship when scanning off vertical (b). Ship operations went well during the deployment despite a rough start. High winds and seas were immediately encountered as the ship headed from Fort Pierce, Florida, to the RICO study area on 28 December. Follow-
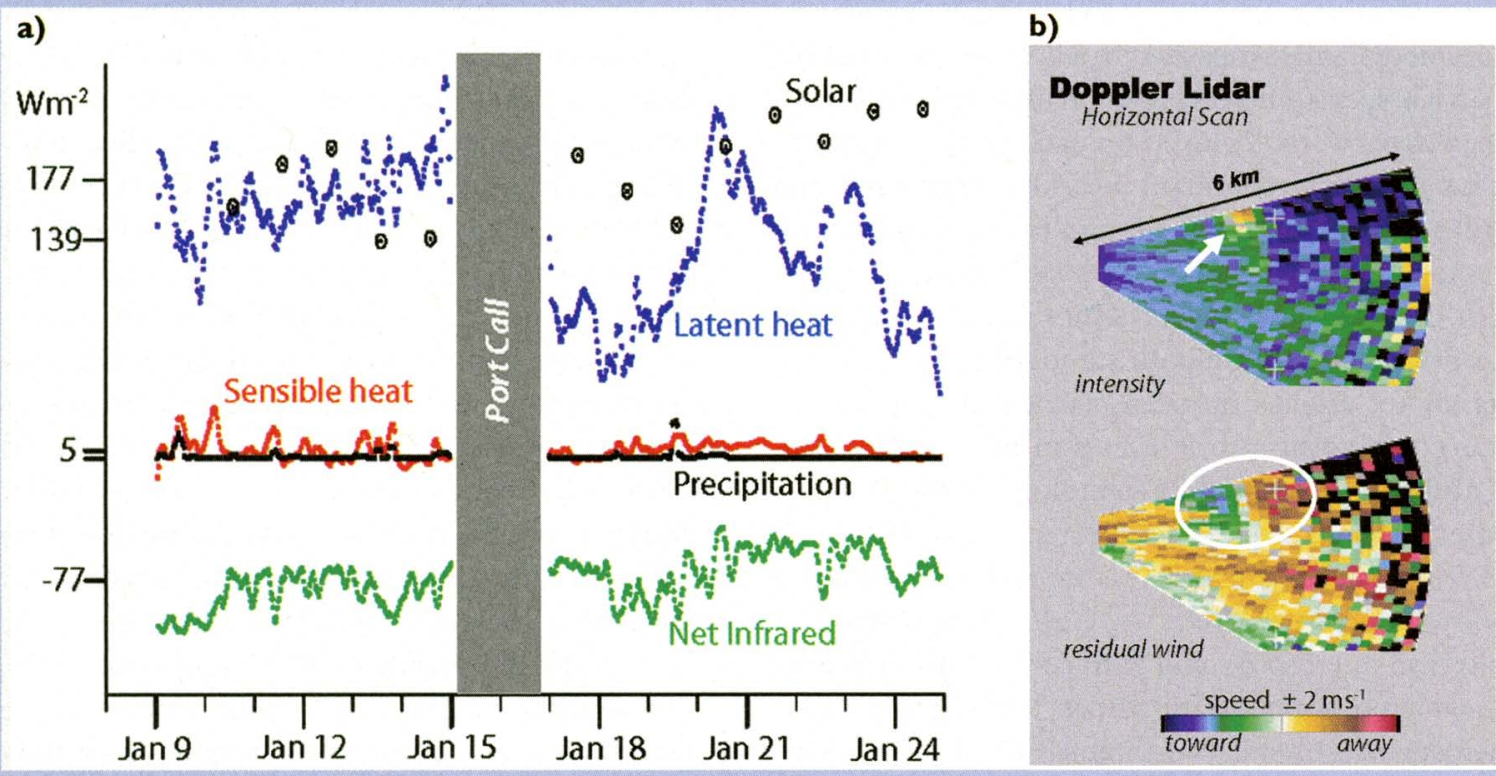
radars provide a much higher resolution representation of a cloud that complements the SPolKa scans. The systematic sampling strategy (especially the subcloud and above-cloud circles of each flight) of the $\mathrm{C} 130$ and extensive sounding data provide a very well sampled physical environment that can be used to explore how environmental factors influence the echo statistics of the trades. Repeated aircraft penetrations of rain shafts and the measurement of drop-size distributions provide the opportunity to tailor rain-rate reflectivity relationships for the RICO period, thereby providing more accurate estimates of rain rate. Last, the integration of all of these data with satellite measurements (e.g., TRMM passed over the SPolKa domain 17 times) helps extend our inferences to larger space and time scales.

Meteorology. LARGe-SCALE CONDITIONS. Aspects of the climatology of the RICO study area are shown in Fig. 1. Near-surface winds blow from the eastnortheast at nearly $7 \mathrm{~m} \mathrm{~s}^{-1}$; sea surface temperatures, calculated following Reynolds et al. (2002), average near $27^{\circ} \mathrm{C}$; and precipitation according to TRMM is light, at less than $2 \mathrm{~mm} \mathrm{day}^{-1}$.

The mean vertical structure of the atmosphere during RICO is illustrated in Fig. 4, which shows the campaign average of the rawinsondes (144 in total) launched from the Spanish Point site on Barbuda between 7 December and 25 January. On average, the atmosphere is weakly unstable to pseudoadiabatic displacements of near-surface parcels. Climatological values of potential temperature at $700 \mathrm{hPa}$ from the 40-yr reanalysis of meteorological data by the ECMWF (Uppala et al. 2005) are about $28^{\circ} \mathrm{C}$, which is quite similar to what was observed. Sea surface temperatures differed from climatological values by less than $0.5^{\circ} \mathrm{C}$. Hence, the stability of the lower troposphere, as measured by the difference between ing a 2-day unscheduled stop in Puerto Rico to repair a failed engine, the ship arrived at the site on 8 January. Scientists, technical staff, graduate and undergraduate students, and a middle school teacher were on the cruise and directed and assisted with operations in an area about $50 \mathrm{~km}$ northeast of Barbuda. This area was chosen to be well within the sampling volume of the NCAR S-band dual-polarization Doppler radar and provided an opportunity to characterize cloud fields and boundary layer structures in this area.

The wide range of cloud and precipitation conditions sampled during the cruise were clearly within the range of conditions expected and needed to accomplish the scientific objectives. Cloud-base heights from the ceilometers along with the lifting condensation levels (LCLs), calculated from $10-\mathrm{m}$ thermodynamic variables, are in good agreement. Corresponding surface fluxes are shown in the panel on the upper left. The Doppler lidar residual velocities and intensities show an example of an outflow boundary sampled from the lidar. The three-panel plot below shows the SPolKa data interpolated to the ship location. This example, for deeper convection than was characteristic of the RICO measurements, helps illustrate the synergy between the ship-based remote sensing, which probed the cloud structure with fine resolution and the ground- or air-based measurements.

Noise at high elevations in the $X$-band image is due to ship motion, which tilts the radar beam off of zenith.

\section{c)}
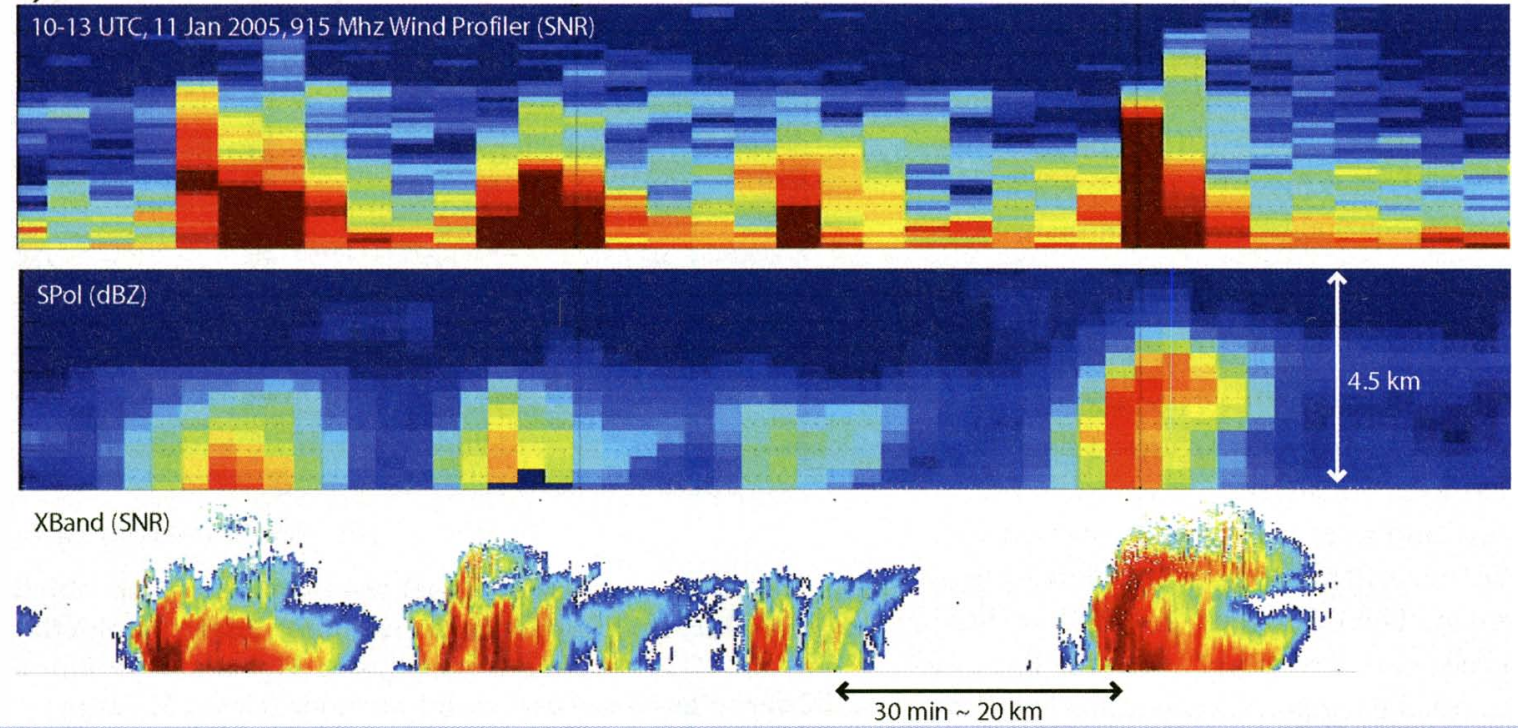

$30 \mathrm{~min} \sim 20 \mathrm{~km}$ 


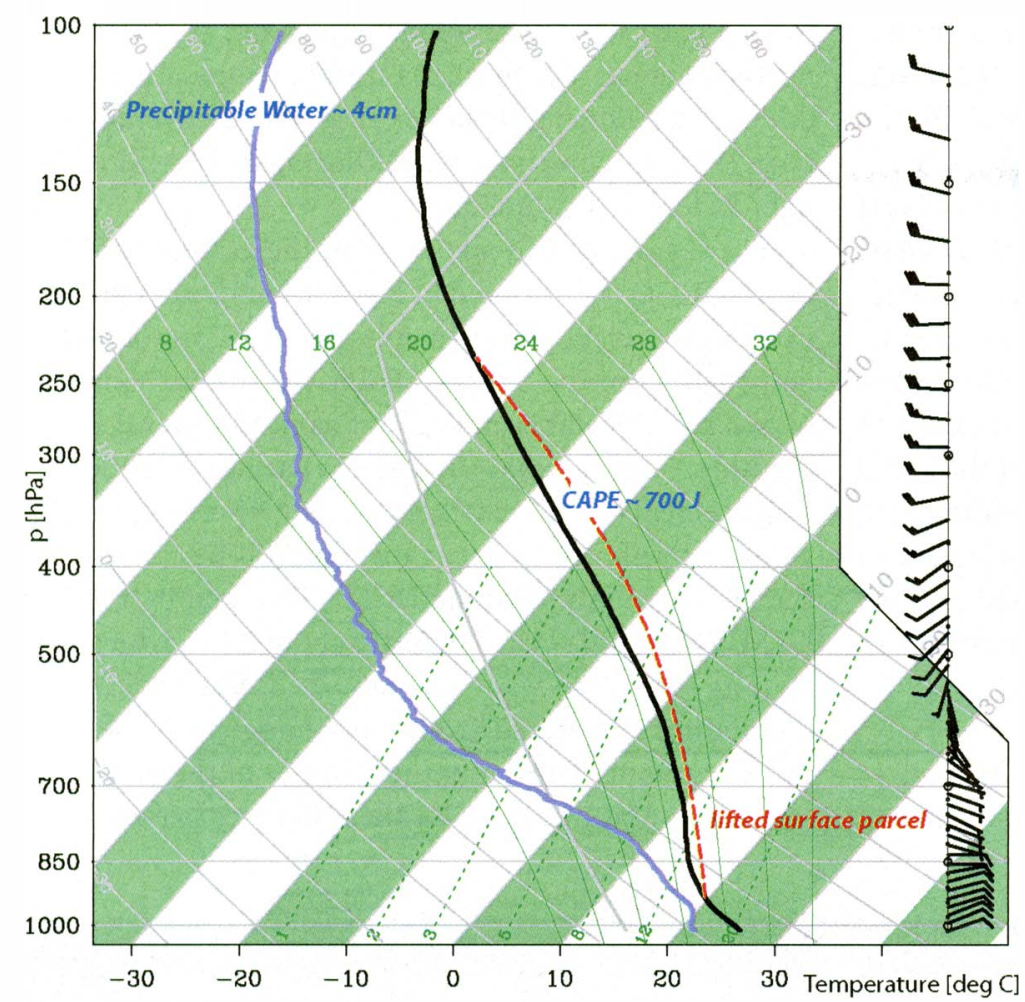

FIG. 4. Skew T-logP diagram showing mean conditions during RICO. than $50 \mathrm{hPa}$ thick, with temperature jumps averaging less than $1 \mathrm{~K}$. Note that the absence of an inversion in the mean skew $T-\log P$ diagram in Fig. 4 is an artifact of the averaging process.

A histogram of the time spent by the $\mathrm{C} 130$ at different levels is given in Fig. 5. The influence of the circles is notable, with about $20 \mathrm{~h}$ spent near the surface, below cloud base, and at the $550-\mathrm{hPa}$ levels. This figure also shows (in red) the time spent in clouds at different levels. As indicated on the figure, deeper congestus clouds, typically organized in lines or small clusters and penetrating to near the freezing level (near $600 \mathrm{hPa}$ ), were common and were sampled by the project aircraft on occasion. Deep-tropospheric convection (tops well above the freezing level, and presumably containing ice) passed through the project area twice. Flight operations were scheduled to avoid these clouds.

To illustrate the nature of the day-

the $700-\mathrm{hPa}$ and surface potential temperatures, was consistent with climatological values. Near-surface winds were characteristic of the ERA-40 climatology, although the observed winds blew from a slightly more northerly direction.

During RICO the trade inversion was less pronounced than expected, for example, from past field studies in the region (Augstein et al. 1973; Nitta and Esbensen 1974). The left graph in Fig. 5 presents a histogram of heights of observed inversion layers, both for flight and all days. To construct this figure the inversion height was defined as the level below $500 \mathrm{hPa}$ where an increase in the virtual temperature is greatest over a $2-\mathrm{hPa}$ interval. In the cases where the temperature was everywhere decreasing below $500 \mathrm{hPa}$ no inversion was recorded. While the histogram shows a peak near $800 \mathrm{hPa}$, consistent with a trade inversion, and a secondary peak near the $0^{\circ} \mathrm{C}$ isotherm, the distributions are quite broad. The inversions observed at these levels were often weak, with the layer of increasing temperatures tending to be less

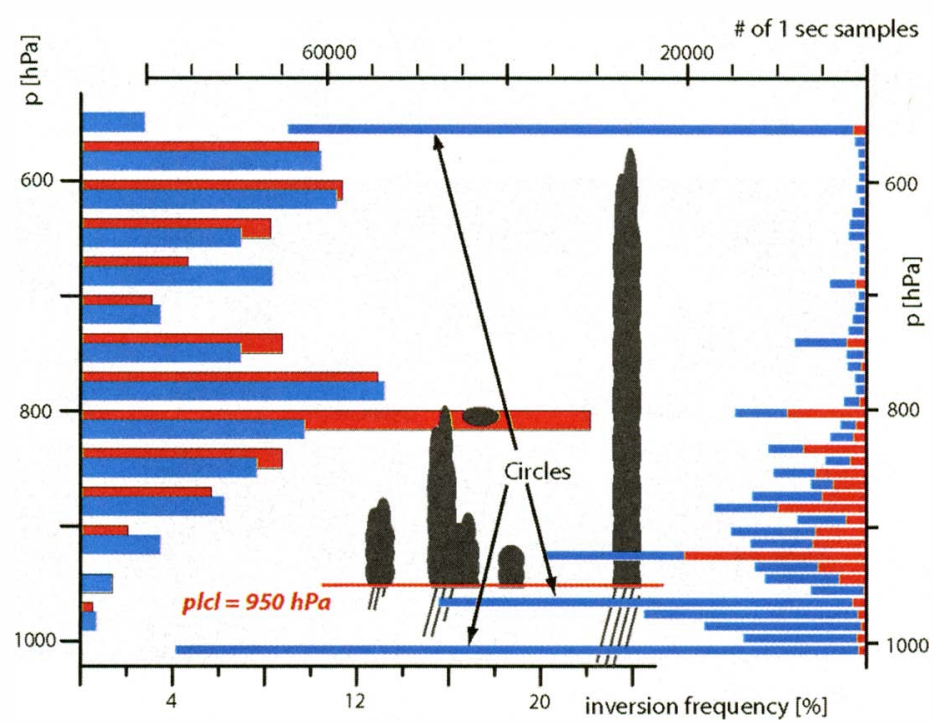

Fig. 5. Histogram showing (left) the frequency with which the inversion locates at a particular height for Spanish Point Sondes (blue) and $\mathrm{Cl} 30$ dropsondes (red), and (right) the number of I-s CI30 samples (blue) and cloud samples (times 5 , red). 
of radar pixels with reflectivity factors greater than $7.5 \mathrm{dBZ}$ are shown in percent as a proxy for rain over the course of the nearly 60 -day field campaign. With only a few exceptions, echo fractions (i.e., the fraction of the entire radar domain where echoes exceeded the $7.5-\mathrm{dBZ}$ threshold) were below $10 \%$, and often below $5 \%$, reflecting trade wind-like convection. The relative paucity of periods with a higher echo fraction (e.g., as were seen in mid-December and around
10 January 2005, and which were associated with deep-tropospheric convection, pronounced upperlevel moisture, and cirrus) was consistent with our expectations for the winter trade wind regime.

Moisture and potential temperature anomalies at $800 \mathrm{hPa}$ are representative of the anomalies nearer the surface. These, as well as mixed-layer wind speed anomalies (e.g., bottom panel of Fig. 3), suggest that the field study sampled a range of conditions. The

\section{GROUND-BASED AEROSOL MEASUREMENTS DURING RICO}

M

easurements were made at three surface stations during RICO to determine the size distribution, spatial variability, and composition of aerosol in the trade wind environment, and to infer how aerosols might impact the microphysics of trade wind cumuli. A particular focus was on the organic component of tropical marine aerosols and their role in forming

CCN. The specific objectives were to determine aerosol size, concentration, and

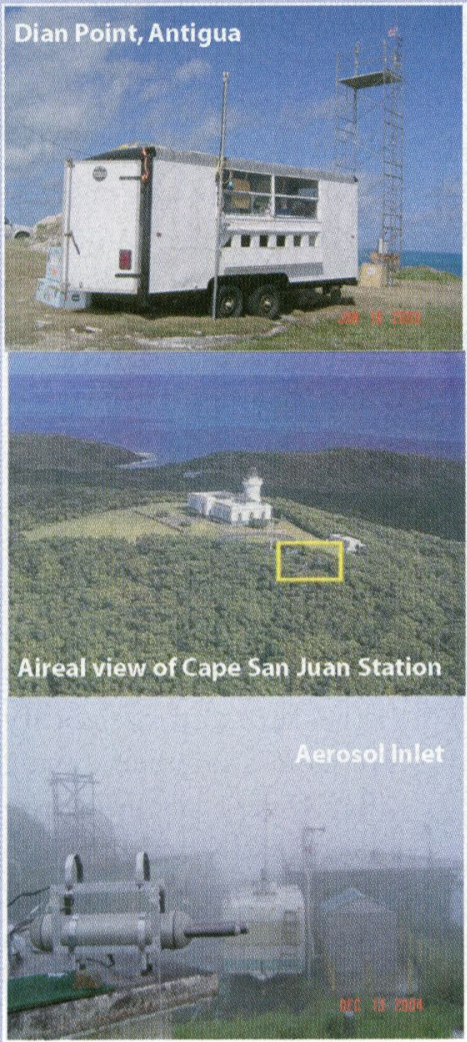
composition, the fraction capable of forming cloud droplets, in-cloud scavenging efficiencies, and surface tension.

Measurements were made in Antigua at Dian Point and at two locations in Puerto Rico - the natural reserve of Cape San Juan and the East Peak mountain site (shown on left). Dian Point is located at the most eastern part of Antigua and Cape San Juan is located at the most northeastern part of Puerto Rico. Antigua and Puerto Rico have good exposure to the easterly trades and are free of major land masses upwind, minimizing the effects of anthropogenic sources. East Peak, downwind of Cape San Juan, is at about 1000-m elevation, and has clouds and precipitation (see third image on left) almost year-round.

Impactors and filter-based samplers were deployed at the Antigua and Puerto Rico stations to collect the aerosol particles for chemical characterization. An example of aerosol composition during a clean period at Dian Point is shown on the bottom left. Impactor substrates were used for size-resolved chemical characterization; samples from filter-based samplers were used for bulk and detailed chemical analysis, and cloud water droplets collected with a cloud water sampler were used for chemical analysis. Total carbon, organic carbon, elemental carbon, water-soluble organic carbon, and water-soluble ions were determined for aerosol and cloud water samples. The concentration and size distribution of particles, and the concentration of CCN were measured, as well as aerosol light absorption, light scattering, and volatility. Size distributions measured with the passive cavity aerosol spectrometer probe throughout January are shown on the bottom left, where evidence of a pollution enhancement to particle sizes near $0.25 \mathrm{~mm}$ is evident in the 20-21 January sample, and dust enhancement of the coarse and accumulation modes is evident in mid-january.

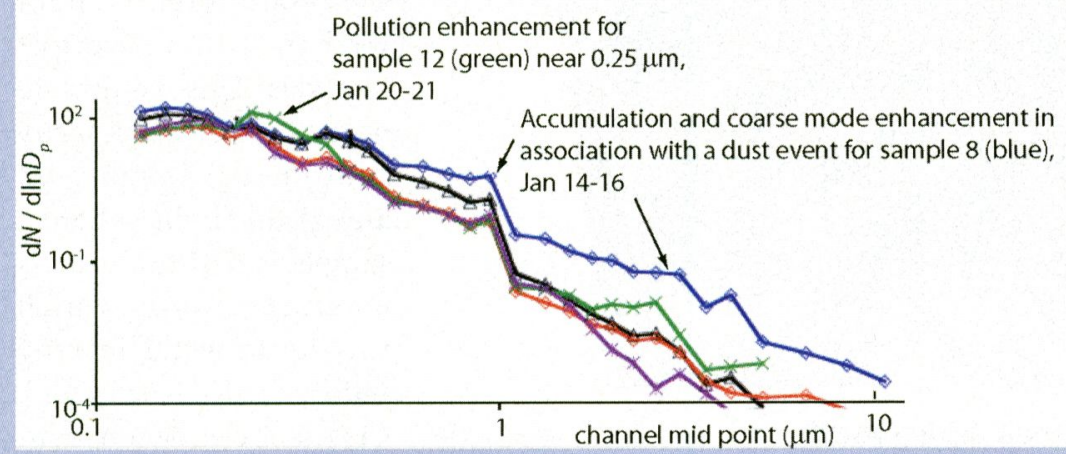

Misc, including $\mathrm{K}^{+}, \mathrm{MSA} \&$ Oxelate

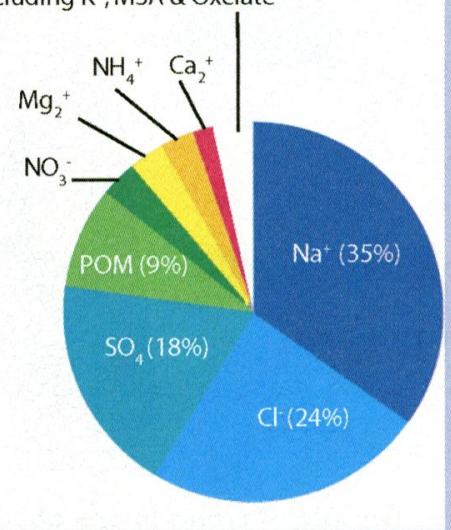


potential temperature anomalies reflect a slight surface cooling (associated with the seasonal cycle) through the course of the campaign. While there is a hint of the periods of deep-tropospheric convection being associated with moister air at $800 \mathrm{hPa}$, the overall relationship between the echo fraction and state of the lower troposphere is subtle. The wide range of wind speeds encountered during the field study proves promising for investigations of the relationship between the sea salt aerosol, whose production rate depends strongly on wind speed (Woodcock 1953; Colón-Robles et al. 2006) and precipitation formation.

Mesoscale organization. As an example of the variety of cloud organizations that were evident over the western Atlantic during RICO, Fig. 6 shows satellite and radar imagery taken at about the same time on 6 January 2005. The images show several common features. Shallow convection with relatively little, or no, measurable precipitation adopted a wide variety of organization, ranging from unorganized (see region marked by the numeral 1 in the figure), to

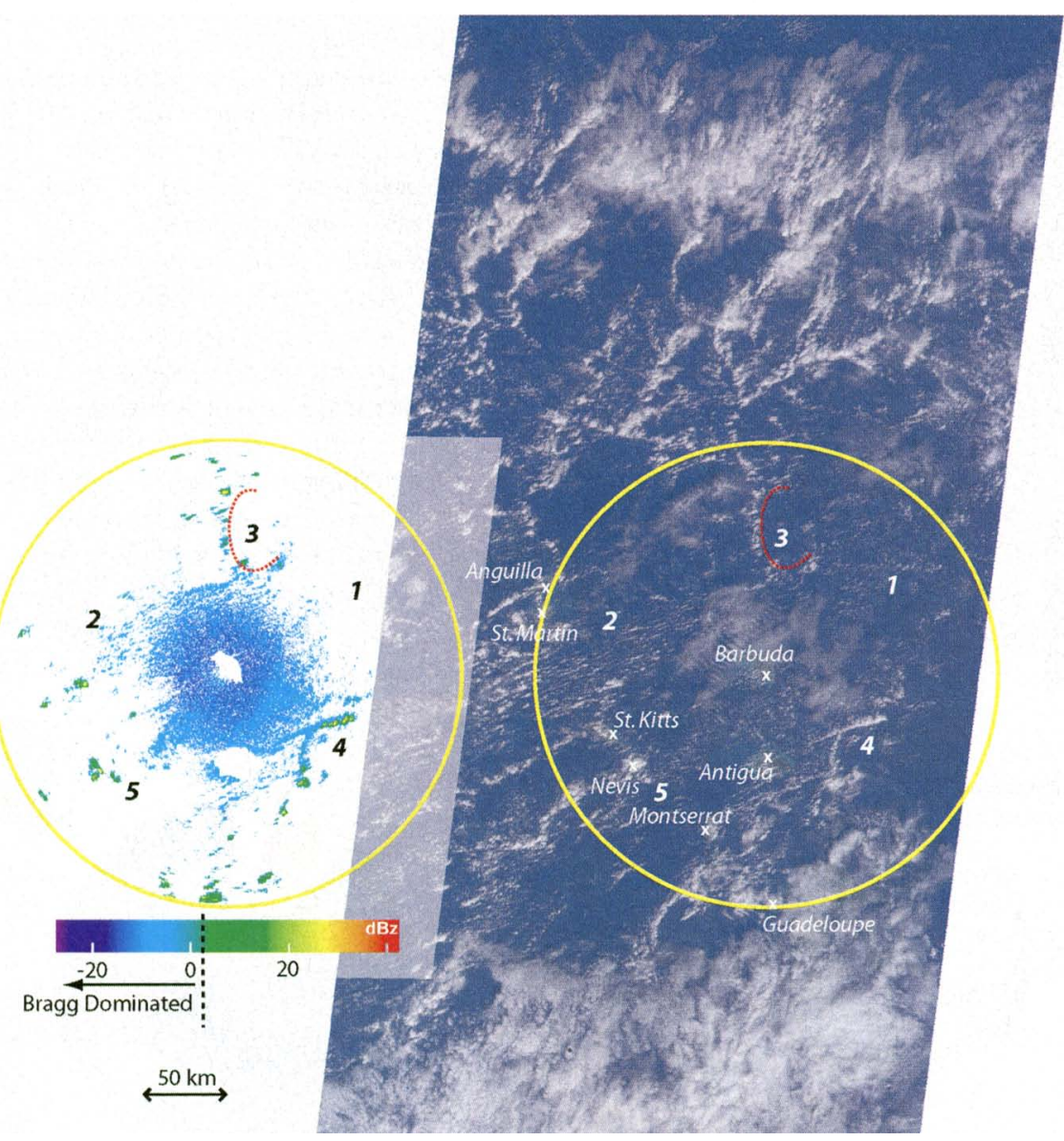

Fig. 6. Sample of cloud forms observed during RICO. wind-parallel cloud streets (numeral 2). Cloud lines downstream from islands were also frequent, as seen from Anguilla, St. Kitts, and Nevis. Deep convection typically occurred south of the study region. In Fig. 6 , regions of deeper convection were prevalent both north and south of the study area, as indicated by regions of more stratiform cloudiness.

Another common feature was the appearance of clouds organized around what appeared to be outflow boundaries from earlier convection. Figure 6 shows two of these, numbered 3 and 4 . Convection associated with these features often reached heights of $3 \mathrm{~km}$ or deeper, and often was organized in a succession of arcs that marched along with the mean wind. Individual outflow lines were long lived (often several hours), and their evolution could easily be traced in the $1-\mathrm{km}$ imagery provided by the Geostationary Operational Environmental Satellite (GOES), which was available at 30-min intervals (cf. Xue et al. 2007). These features on radar often gave the impression of a distinct line, which, upon inspection of the satellite image, revealed itself to be a more arc-shaped outflow. An example, numbered 3, is highlighted north of Barbuda. Where either arcs intersected or other perturbations to the flow existed (such as the Islands), deeper clusters sometimes formed, an example evident in feature 5 .

Microstructure. To give a sense of the microphysical structure and variability of clouds sampled during RICO, Fig. 7 shows the liquid water mixing ratio and droplet number concentrations in cloud cores sampled by the C130. Here the cloud core is defined by the 95th percentile in the liquid water content within $100-\mathrm{m}$-height intervals. This requires 40 or more (not necessarily contiguous) samples on any given flight, where a sample is defined as a 1-s measurement for which the liquid water mixing ratio exceeded $0.025 \mathrm{~g} \mathrm{~kg}^{-1}$. Closed circles denote non- 
precipitating samples, that is, those for which no drops were recorded by the two-dimensional precipitation probe. Because the shattering of raindrops can bias droplet concentration measurements by the forward-scattering probes, only nonraining samples were used to estimate droplet concentrations.

The data paint a familiar picture of trade cumulus clouds. Overall, even the wettest $100-\mathrm{m}$ cores are far from adiabatic; liquid water contents in nonraining regions rarely reached as high as $1 \mathrm{~g} \mathrm{~kg}^{-1}$. A comparison of diamonds and filled circles in the left-hand panel of Fig. 7 shows that above $2000 \mathrm{~m}$ it becomes increasingly difficult to find $100-\mathrm{m}$ regions within clouds that are devoid of raindrops. Moreover, the wetter samples are increasingly likely to contain rain as one ascends within the cloud. The air masses were decidedly maritime in character as droplet concentrations varied by an order of magnitude but tended to cluster near $100 \mathrm{~cm}^{-3}$ (Fig. 7, right panel). Initial analyses of (CCN) concentrations at $1 \%$ of supersaturation, from an analysis of circles in the subcloud layer of 13 of the 19 C130 flights, appear consistent with the cloud-droplet measurements and their flight-to-flight variations. The data also hint at some of the challenges that subsequent analyses must overcome. On $\mathrm{C} 130$ flights where data from both the fast FSSP and the standard EOL FSSP are available, the data are well correlated but differ by nearly a factor of 2 (Fig. 7, right panel). Systematic, albeit much smaller, differences are also evident in the liquid water measurements by the two King probes (shown by red and blue, respectively) mounted on the $\mathrm{C} 130$.

IMPRESSIONS. Working in the field has the tendency to disabuse one of their preconceptions. In this regard we close by touching on a few of the many impressions that have emerged from our field experiences, which are guiding ongoing inquiry and analysis. To the extent that these impressions are not truly novel, we include them as points of emphasis.

A particular impression was that the trades of the wintertime western Atlantic encompassed many levels, which brings to mind Riehl's (1954) cartoon showing trade cumulus as but one of the common forms of clouds found in the trades (cumulus humilis, congestus, and chimney clouds being other common forms). Although clouds most frequently topped near $800 \mathrm{hPa}$ in conjunction with the presence of a weak stable layer (e.g., Fig. 5), inversion layers manifest themselves intermittently and at a variety of levels. Convection that reached to $700 \mathrm{hPa}$ crossed the radar domain almost every day, and precipitation outflow boundaries that originated with this and deeper convection often seemed to play a role in initiating and organizing convection (Snodgrass 2006). While the clouds were most dominant in shallow layers and rain ensued from regions where the cloud layer was somewhat deeper, wind profiles imply that the thermal structure of the lower troposphere (below $500 \mathrm{hPa}$ ) was differentiated from that of the upper troposphere, perhaps indicative of the role played by convection that reached to the level of $\theta_{e}$ minimum near $500 \mathrm{hPa}$.

Another striking impression was the degree to which convection lacked a clear temporal origin. Thermals often emerged from the debris of their predecessors, thus making it more difficult to relate their initial droplet spectrum to the properties of the subcloud aerosol. Well-defined patches of clouds were observed by satellite over periods of many hours and radar observations showed many cycles of echoes within a single patch of clouds. As a result, clouds 
often gave the impression as consisting of multiple pulses (successions of thermals), whose lifetimes are much shorter than that of the cloud and whose scales can also be smaller, both of which complicate attempts to ascribe clear beginnings and endings to the microphysical evolution of clouds.

Measurements during RICO also confirmed an impression of clouds in the trades as being capable of producing significant amounts of rain from clouds with relatively little liquid water. Cloud liquid water contents rarely exceeded $1 \mathrm{~g} \mathrm{~kg}^{-1}$ (e.g., Fig. 7). Indeed, liquid water contents measured in stratocumulus during the DYCOMS-II field study (Stevens et al. 2003) were sometimes higher than that observed during RICO. Initial analyses of radar data (Nuijens 2005; Snodgrass 2006) suggest that nearly half of the total rain that was observed was associated with two periods of much deeper convection (e.g., in mid-December and around 8 January in Fig. 3); even so, this attributes roughly half of the rain observed during RICO to shallower clouds, for which areaaveraged rain rates averaged less than $3 \mathrm{~mm}$ day $^{-1}$. Overall, the echo coverage tended to be less than $2 \%$ of the observed area, but with ongoing analysis suggesting the emergence of an early morning peak (Snodgrass 2006).

Last, efforts since the field phase bode well for the use of RICO data to help advance modeling efforts. Data from RICO are providing context for idealized studies of the microphysical evolution of pulses and thermals (e.g., Lasher-Trapp et al. 2005), as well as novel methods of representing entrainment and mixing processes in numerical simulations (e.g., Krueger et al. 1997). RICO data are already making their mark on cloud field simulations. Studies at the U.K.'s Met Office have been using RICO measurements to evaluate warm-rain representations in cloud-resolving models (Abel and Shipway 2007), and composite data from RICO are being used as a test case for both the 10th intercomparison of the GEWEX Cloud System Study (GCSS) boundary layer working group, as well as regional-scale climate studies. Noteworthy in these respects is the degree to which RICO measurements are already serving as both a catalyst and a constraint on the interactions of diverse communities, ranging from numerical modelers to cloud physicists and observationalists.

In summary, the RICO data provide a wealth of information on the structure, evolution, and amount of precipitation in the cumuli of the trades, and the environmental conditions with which they are associated. The unprecedented array of instrumentation deployed during RICO to document this struc- ture also presents great challenges of interpretation. (Readers interested in how instrumental issues contribute to these challenges are referred to a summary in the electronic supplement online at doi:10.1175/ BAMS-88-12-Rauber.) Clues to many of the mysteries we hope to unravel may lie within the intersection of datasets that (because they sample such a wide range of processes over such a wide range of scales) are not necessarily heterogeneous. This poses challenges for the analysis. Nonetheless, the conditions were favorable to our objectives, and the data for the most part lived up to our expectations. In particular, RICO succeeded in providing some of the first measurements of the drop-size distributions at a variety of levels in a large number of clouds in different stages of development, all within a well-constrained large-scale environment and under the watchful gaze of multitudes of remote sensors. For these reasons we are optimistic about the ability of the RICO measurements to advance our understanding of rain in shallow convection over the ocean.

ACKNOWLEDGMENTS. Funding for RICO was provided by the National Science Foundation under NSF-ATM Grants 0346172, 0336849, 342623, 034258, 0342648, 0342486, 0531740, 0342651, 0526600, 0342597, 0345694, 0342386, 0342618,0346854, 0342421, and 0312036. The authors thank the many scientists and staff of the National Center for Atmospheric Research Earth Observing Laboratory for all their efforts in making RICO a success. We also thank the staff of the Wyoming King Air, the FAAM BAE146, and the Research Vessel Seward Johnson for their contributions to the field campaign, as well as the staff and scientists of the NOAA Earth System Research Laboratory who helped support the Seward Johnson deployment. The FAAM BAE146 aircraft and its participation in RICO was jointly funded by the Met Office and the Natural Environment Research Council. NOAA OI SST V2 data provided by the NOAA/OAR/ESRL PSD, Boulder, Colorado, from their Web site. TRMM data were downloaded from the NASA GES Distributed Active Archive Center. The National Center for Atmospheric Research is funded by the National Science Foundation. Any opinions, findings, and conclusions are those of the authors and do not necessarily reflect the views of the National Science Foundation.

\section{REFERENCES}

Abel, S., and B. Shipway, 2007: A comparison of cloud resolving model simulations of trade wind cumulus with aircraft observations taken during RICO. Quart. J. Roy. Meteor. Soc., 133, 781-794. 
Albrecht, B. A., 1989: Aerosols, cloud microphysics and fractional cloudiness. Science, 245, 1227-1230.

Augstein, E., H. Riehl, F. Ostapoff, and V. Wagner, 1973: Mass and energy transports in an undisturbed Atlántic trade-wind flow. Mon. Wea. Rev., 101, 101-111.

Baker, M. B., and J. Latham, 1979: The evolution of droplet spectra and rate of production of embryonic raindrops in small cumulus clouds. J. Atmos. Sci., 36, 1612-1615.

Betts, A. K., 1973: Non-precipitating cumulus convection and its parameterization. Quart. J. Roy. Meteor. Soc., 99, 178-196.

Blyth, A. M., 1993: Entrainment in cumulus clouds. J. Appl. Meteor., 32, 626-641.

Bony, S., and J.-L. Dufresne, 2006: Marine boundary layer clouds at the heart of tropical cloud feedback uncertainties in climate models. Geophys. Res. Lett., 32, L20806, doi:10.1029/2005GL023851.

Brenguier, J.-L., and V. W. Grabowski, 1993: Cumulus entrainment and cloud droplet spectra: A numerical model within a two-dimensional dynamical framework. J. Atmos. Sci., 50, 120-136.

— , T. Bourrianne, A. de Araujo Coelho, R. Jacques Isbert, R. Peytavi, D. Trevarin, and P. Weschler, 1998: Improvements of droplet distribution size measurements with the fast-FSSP (forward scattering spectrometer probe). J. Atmos. Oceanic Technol., 15, 1077-1090.

Byers, H. R., and R. K. Hall, 1955: A census of cumulus-cloud height versus precipitation in the vicinity of Puerto Rico during the winter and spring of 1953-1954. J. Meteor., 12, 176-178.

Colón-Robles, M., R. M. Rauber, and J. B. Jensen, 2006: The influence of low-level wind speed on droplet spectra near cloud base in trade wind $\mathrm{cu}-$ mulus. Geophy. Res. Lett., 33, L20814 doi:10.1029/ 2006 GL027487.

Cooper, W. A., 1989: Effects of variable droplet growth histories on droplet size distributions. Part I: Theory. J. Atmos. Sci., 46, 1301-1311.

Faloona, I., and Coauthors, 2005: Observations of entrainment in eastern Pacific marine stratocumulus using three conserved scalars. J. Atmos. Sci., 62, 3268-3285.

Houghton, H. G., 1938: Problems connected with the condensation and precipitation processes in the atmosphere. Bull. Amer. Meteor. Soc., 19, 152-159.

Johnson, D. B., 1982: The role of giant and ultragiant aerosol particles in warm rain initiation. J. Atmos. Sci., 39, 448-460.

Knight, C. A., and L. J. Miller, 1998: First radar echoes and the early $\mathrm{z}_{d} r$ history of Florida cumulus early radar echoes from small, warm cumulus: Bragg and hydrometeor scattering. J. Atmos. Sci., 55, 2974-2992.

Kogan, Y. L., 1993: Drop size separation in numerically simulated convective clouds and its effect on warm rain formation. J. Atmos. Sci., 50, 1238-1253.

Krueger, S. K., C.-W. Su, and P. A. McMurtry, 1997: Modeling entrainment and finescale mixing in cumulus clouds. J. Atmos. Sci., 54, 2697-2712.

Lasher-Trapp, S., W. A. Cooper, and A. M. Blyth, 2005: Broadening of droplet size distributions from entrainment and mixing in a cumulus cloud. Quart. J. Roy. Meteor. Soc., 131, 195-220.

Latham, J., and R. L. Reed, 1977: Laboratory studies of the effects of mixing on the evolution of cloud droplet spectra. Quart. J. Roy. Meteor. Soc., 103, 297-306.

Lawson, R. P., D. O'Connor, P. Zmarzly, K. Weaver, B. Baker, Q. Mo, and H. Jonsson, 2006: The 2D-S (stereo) probe: Design and preliminary tests of a new airborne, high-speed, high-resolution particle imaging probe. J. Atmos. Oceanic Technol., 23, 1462-1477.

Ludlam, F. H., and P. M. Saunders, 1956: Shower formation in large cumulus. Tellus, 8, 424-442.

Neggers, R. A., J. D. Neelin, and B. Stevens, 2007: Impact mechanisms of shallow cumulus convection on tropical climate dynamics. J. Climate, 20, 2623-2642.

Nitta, T., and S. Esbensen, 1974: Heat and moisture budget analyses using BOMEX data. Mon. Wea. Rev., 102, 17-28.

Nuijens, L., 2005: Estimating precipitation from radar observations in the trade-wind cumulus region. M.S. thesis, Meteorology and Air Quality Research Section, Wageningen University and Research Center, $46 \mathrm{pp}$.

Rauber, R. M., K. V. Beard, and B. M. Andrews, 1991: A mechanism for giant raindrop formation in warm shallow convective clouds. J. Atmos. Sci., 48, 1791-1797.

Reynolds, R. W., N. A. Rayner, T. M. Smith, D. C. Stokes, and W. Wang, 2002: An improved in situ and satellite SST analysis for climate. J. Climate, 15, 1609-1625.

Riehl, H., 1954: Tropical Meteorology. McGraw-Hill, $392 \mathrm{pp}$.

—, C. Yeh, J. S. Malkus, and N. E. LaSeur, 1951: The north-east trade of the Pacific Ocean. Quart. J. Roy. Meteor. Soc., 77, 598-626.

Saunders, P. M., 1965: Some characteristics of tropical marine showers. J. Atmos. Sci., 22, 167-175.

Shaw, R. A., 2003: Particle-turbulence interactions in atmospheric clouds. Annu. Rev. Fluid Mech., 35, $183-227$. 
Short, D. A., and K. Nakamura, 2000: TRMM radar observations of shallow precipitation over the tropical oceans. J. Climate, 13, 4107-4124.

Siebesma, A. P., 1998: Shallow cumulus convection. Buoyant Convection in Geophysical Flows, E. J. Plate et al., Eds., Kluwer Academic, 441-486.

Snodgrass, E. R., 2006: Precipitation characteristics from trade wind clouds during RICO derived from radar, satellite and aircraft measurements. M.S. thesis, Dept. of Atmospheric Science, University of Illinois, Urbana-Champaign, $101 \mathrm{pp}$.

Squires, P., 1958: The microstructure and colloidal stability of warm clouds: Part I-The relation between structure and stability. Tellus, 10, 256-261.

Srivastava, R. C., 1989: Growth of cloud drops by condensation: A criticism of currently accepted theory and new approach. J. Atmos. Sci., 46, 869-887.

Stevens, B., 2005: Atmospheric moist convection. Ann. Rev. Earth Planet. Sci., 33, 605-643.

- 2007: On the growth of layers of nonprecipitating cumulus convection. J. Atmos. Sci., 64, 2916-2931.

—, and Coauthors, 2003: DYCOMS-II. Bull. Amer. Meteor. Soc., 84, 579-593.

Stommel, H., 1947: Entrainment of air into a cumulus cloud. J. Meteor., 4, 91-94.
Telford, J. W., T. S. Keck, and S. K. Chai, 1984: Entrainment at cloud tops and the droplet spectra. J. Atmos. Sci., 41, 3170-3179.

Tiedtke, M., 1989: A comprehensive mass flux scheme for cumulus parameterization in large-scale models. Mon. Wea. Rev., 117, 1779-1800.

Twohy, C., A. J. Schanot, and W. A. Cooper, 1997: Measurement of condensed water content in liquid and ice clouds using an airborne counterflow virtual impactor. J. Atmos. Oceanic Technol., 14, 197-202.

Uppala, S. M., and Coauthors, 2005: The ERA-40 reanalysis. Quart. J. Roy. Meteor. Soc., 131, 29613012.

Woodcock, A. H., 1953: Salt nuclei in marine air as a function of altitude and wind force. J. Meteor., 10, $362-471$.

Wyant, M. C., C. S. Bretherton, J. T. Backmeister, J. T. Kiehl, I. M. Held, S. A. Klein, and B. J. Soden, 2006: A comparison of low-latitude cloud properties and their response to climate change in three AGCMs sorted into regimes using mid-tropospheric vertical velocity. Climate Dyn., 27, 261-279.

Xue, H., G. Feingold, and B. Stevens, 2007: Aerosol effects on clouds, precipitation, and the organization of shallow cumulus convection. J. Atmos. Sci., in press.

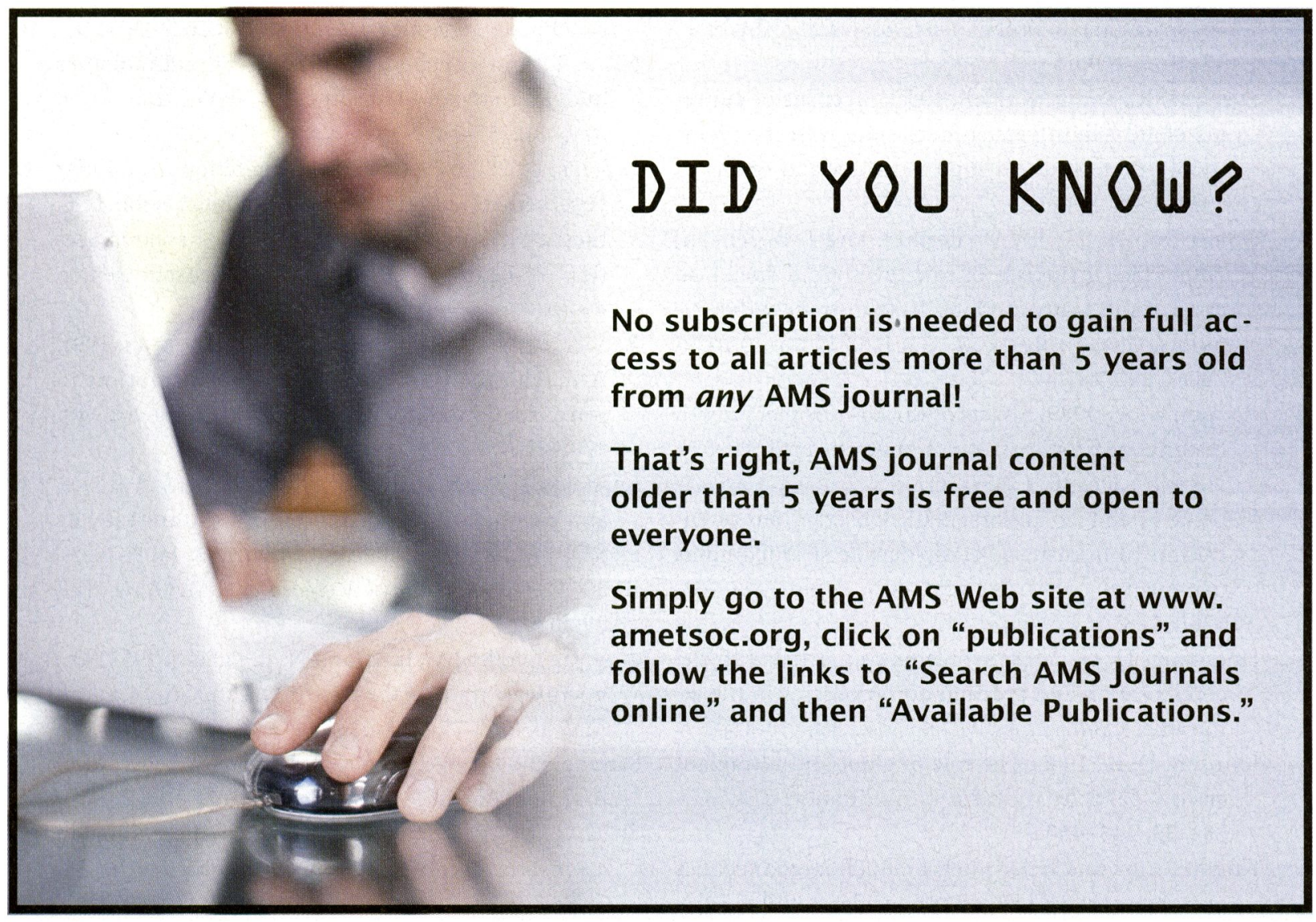

